\title{
Fitoquímicos em amora-preta (Rubus spp)
}

\section{Phytochemicals in blackberry}

\author{
Andressa Carolina Jacques ${ }^{1 *}$; Rui Carlos Zambiazi ${ }^{2}$
}

\begin{abstract}
Resumo
Dentre as opções de espécies frutíferas com perspectivas de comercialização, a amoreira-preta (Rubus spp) se destaca como uma das mais promissoras. Esta é uma das espécies que tem apresentado um crescimento de área cultivada nos últimos anos no Rio Grande do Sul (principal produtor brasileiro). O consumo regular de frutas e hortaliças está associado com o baixo risco de incidência e mortalidade por câncer e doenças cardíacas, devido à presença de compostos oriundos do metabolismo secundário, especialmente flavonóides e antocianinas, os quais apresentam grande capacidade de reagir com radicais livres que causam estresse oxidativo, e portanto, contribuem na prevenção destas doenças. $\mathrm{Na}$ identificação dos compostos fenólicos na amora-preta foram encontrados os ácidos fenólicos e flavonóides. Dentre os flavonóides encontrados, destacam-se as antocianinas, que variam em sua concentração de acordo com o estágio de maturação das frutas. Tendo como base os valores encontrados na literatura sobre antocianinas e a grande variação entre os diferentes materiais genéticos, existe um grande potencial na produção de amora-preta visando a sua utilização como corante natural na indústria alimentícia e de medicamentos. Além dos compostos fenólicos, a amora-preta também apresenta outros fitoquímicos como às vitaminas $\mathrm{C} \mathrm{e} \mathrm{E}$, além de carotenóides. Este trabalho tem como objetivo fazer uma revisão bibliográfica dos principais fitoquímicos presentes na amora-preta (Rubus spp).
\end{abstract}

Palavras-chave: Amora-preta, fitoquímicos, antioxidantes

\begin{abstract}
Among the options for fruit species with market prospects, the blackberry (Rubus spp) stands out as one of the most promising. This is a species that has shown an increase of cultivated area in recent years in Rio Grande do Sul (main Brazilian producer). Regular consumption of fruits and vegetables is associated with low risk of incidence and mortality from cancer and heart disease due to the presence of compounds derived from secondary metabolism, especially flavonoids and anthocyanins, which have great capacity to react with free radicals that cause oxidative stress, and therefore contribute to the prevention of these diseases. The phenolic acids and flavonoids were identificated in the group of phenolic compounds in blackberry. Among the flavonoids, stands out the anthocyanins, which vary in concentration according to the stage of maturation of fruits. Based on the antocyanin content related in literature and the great variation between different genetic materials, there is great potential in the production of blackberry and its utilization as a natural colorant in the food and pharmaceuticals industry. In addition to these compounds, the blackberry also has other phytochemicals such as vitamin $\mathrm{C}$, vitamin $\mathrm{E}$ and carotenoids. This paper aims to review literature of the main phytochemicals in blackberry (Rubus spp).
\end{abstract}

Key words: Blackberry, phytochemicals, antioxidants

1 Doutoranda do Departamento Ciência e Tecnologia Agroindustrial. Universidade Federal de Pelotas, UFPEL. E-mail: andressa. jacques@yahoo.com.br

2 Prof. Titular Departamento de Ciência dos Alimentos. Universidade Federal de Pelotas, UFPEL. E-mail: zambiazi@gmail.com Autor para correspondência 


\section{Introdução}

A mudança no hábito alimentar da população brasileira, observada nos últimos anos, tem proporcionado um novo nicho de mercado de frutas frescas. A produção brasileira das principais espécies frutíferas de clima temperado é insuficiente para atender a demanda interna, gerando uma crescente necessidade de importação de frutas que, na sua grande maioria, poderiam ser produzidas no Brasil (ANTUNES, 2002).

Dentre as opções de espécies frutíferas com perspectivas de aumento de produção e aumento de oferta para a comercialização, a amoreirapreta (Rubus spp) se destaca como uma das mais promissoras. Esta é uma das espécies que tem apresentado um crescimento de área cultivada nos últimos anos no Rio Grande do Sul (principal produtor brasileiro), mas apresenta alto potencial de cultivo em regiões de clima temperado e subtropical, como nos estados de Santa Catarina, Paraná, São Paulo e Sul de Minas Gerais. Devido ao baixo custo de implantação e de manutenção do pomar e, principalmente, pela reduzida utilização de defensivos agrícolas, esta cultura se apresenta como opção para a agricultura familiar. $\mathrm{O}$ cultivo da amoreira-preta caracteriza-se pelo retorno rápido, pois no segundo ano de plantio inicia a produção, proporcionando ao pequeno produtor opções de renda, pela destinação do produto ao mercado "in natura", e também como matériaprima para indústrias processadoras de alimentos, como indústrias de produtos lácteos, de congelados e conserveiras (ANTUNES, 2002).

A amora-preta “in natura” é altamente nutritiva, contendo $85 \%$ de água, $10 \%$ de carboidratos, elevado conteúdo de minerais, de vitaminas do complexo B, vitamina A e cálcio. Estes frutos podem ser consumidos na forma de sub-produtos como geléias, sucos, e como ingrediente em sorvetes e iogurtes (POLING, 1996).

Uma série de funções e constituintes químicos são relatados na literatura internacional relacionados às qualidades da amora-preta, estando, entre eles, o ácido elágico (ANTUNES, 2002). O ácido elágico é um derivado do ácido gálico, e como fenol, possui algumas propriedades de compostos fenólicos (WANG et al., 1994). Segundo Wang et al. (1994), o ácido elágico (C14H6O8) é encontrado em morango (Fragaria spp), groselha preta (Ribes nigrum), amoreira-preta (Rubus subgênero Eubatus), framboesa (Rubus subgênero Idaeobatus), entre outras espécies. O ácido elágico e alguns elagitaninos têm mostrado propriedades inibidoras contra replicação do vírus HIV transmissor da Aids Maas, Galleta, e Stoner (1991).

Além dos nutrientes essenciais e dos micronutrientes, as frutas contribuem com diversos componentes oriundos de metabólicos secundários, principalmente os de natureza fenólica, denominados de polifenóis. O consumo regular de frutas e hortaliças está associado com o baixo risco de incidência e mortalidade por câncer e doenças cardíacas, devido à presença de compostos oriundos do metabolismo secundário, especialmente flavonóides e antocianinas, os quais apresentam grande capacidade de reagir com radicais livres, e portanto, contribuem na prevenção de várias doenças. Estes compostos apresentam ainda, atividade anti-inflamatória, antialérgica, antitrombótica, antimicrobiana e antineoplásica (KUSKOSKI et al., 2005).

Os antioxidantes podem ser divididos em duas classes: os que apresentam atividade enzimática e os que não apresentam atividade enzimática. Na primeira, estão incluídos os compostos capazes de bloquear a iniciação da oxidação, ou seja, as enzimas que removem as espécies reativas ao oxigênio. $\mathrm{Na}$ segunda classe, estão incluídas moléculas que interagem com as espécies radicalares, as quais são consumidas durante a reação; incluindo os antioxidantes naturais e sintéticos, como os compostos fenólicos (MOREIRA; MANCINIFILHO, 2004).

Os compostos fenólicos presentes nas plantas 
são essenciais para o crescimento e reprodução dos vegetais, além de atuarem como agentes antipatogênicos e contribuírem na pigmentação, adstringência e estabilidade oxidativa. Dentre os compostos fenólicos do grupo dos flavonóides se encontram as antocianinas. As antocianinas são pigmentos que conferem uma coloração que varia entre o laranja, vermelho e azul. Segundo Shahidi e Marian (2003), estudos recentes demonstram que as antocianinas atuam como antioxidantes naturais, promovendo vários benefícios à saúde.

Além das antocianinas, os carotenóides também possuem capacidade antioxidante, apesar de estarem presentes em baixas quantidades na amora-preta. De acordo com Azevedo-Meleiro e RodriguezAmaya (2004), a cor e a atividade biológica dos carotenóides estão intrinsecamente relacionados com sua estrutura molecular. $\mathrm{O}$ consumo de frutas e hortaliças com alto teor de carotenóides tem apresentado, também, uma relação inversa com o risco de desenvolvimento de câncer (KRINSKY, 1989, 1991).

Além dos compostos fenólicos e carotenóides, a amora-preta ainda apresenta tocoferóis, os quais ocorrem naturalmente em praticamente todos os vegetais, principalmente nos vegetais verdeescuros, nas sementes oleaginosas, nos óleos vegetais e no gérmem de trigo; e a vitamina $\mathrm{C}$ ou ácido L-ascórbico (AA), que é uma vitamina hidrossolúvel e termolábil amplamente distribuída nos vegetais e em produtos de origem vegetal, sendo encontrada, principalmente, em frutas cítricas e hortaliças folhosas (ZHANG; HAMAUZU, 2004).

Em face do exposto, esta revisão tem como objetivo apresentar os principais fitoquímicos presentes na amora-preta (Rubus spp) e os efeitos na saúde.

\section{Amora-Preta}

A amoreira-preta (blackberry) pertence ao gênero Rubus que contém aproximadamente 740 espécies que são subdivididas segundo alguns autores em 12 subgêneros, e segundo outros autores em 15 subgêneros (DAUBENY, 1996). Esta frutífera possui porte ereto ou rasteiro, a qual produz frutos agregados, formado por mini-drupas com cerca de quatro a sete gramas, de coloração negra e sabor ácido a doce-ácido.

O cultivo da amoreira-preta começou na segunda metade do século XIX nos Estados Unidos, onde é conhecida como blackberry. No Brasil, as primeiras cultivares foram introduzidas em 1972, no Centro de Pesquisa da Embrapa Clima Temperado, localizada em Pelotas-RS. Esta cultura apresentou boa adaptação e tem alcançado alta produtividade devido às condições climáticas desta região, a qual permite o cultivo de frutas das espécies de clima temperado (ANTUNES, 2002; ANTUNES; RASEIRA, 2004; NACHTIGALL et al., 2004). Além das cultivares inicialmente introduzidas, Brazos, Comanche e Cherokee, a Embrapa Clima Temperado desenvolveu um programa de melhoramento genético, originando as cultivares Ébano, Negrita, Tupy, Guarani, Cainguangue e Xavante (SANTOS; RASEIRA; MADAIL, 1997).

Segundo relatos de Chim (2008), atualmente a cultivar Tupy é mais cultivada no Brasil, a qual resultou do cruzamento das cultivares Uruguai e Comanche, realizado pela Embrapa Clima temperado em 1982. A colheita destas frutas ocorre entre meados de novembro a início de janeiro.

A amora-preta apresenta valores de $\mathrm{pH}$ de 2,33, para a cultivar Wild da região do Patzcuaro/México (REYES-CARMONA et al., 2005), a valores de 3,40 para amora-preta de cultivares da região de Pelotas/RS/Brasil (JCQUES, 2009). Estudos realizados em Thessaloniki na Grécia, relatam variações no conteúdo de sólidos solúveis de cultivares não mencionadas de amora-preta (Rubus fruticousus) de 9,8 à 11,5\% (PANTELIDIS et al., 2007). Mota (2006a), relata variações no conteúdo de sólidos solúveis de 7,60 à 10,37\% em amorapreta de diversas cultivares oriundas da Estação 
Experimental de Caldas em Poços de Caldas/ Minas Gerais/Brasil. Jacques (2009) relata valores de acidez de $0,11 \%$ (em ácido cítrico) para amorapreta da cultivar Tupy oriunda da cidade de Pelotas/ $\mathrm{RS} /$ Brasil, no entanto, Mota (2006a) relata valores de acidez de 1,33\% (em ácido cítrico) para amorapreta da mesma cultivar oriunda da cidade de Poços de Caldas/MG/Brasil, demonstrando a grande variabilidade no conteúdo de acidez que ocorre em frutos cultivados em locais com climas distintos. De acordo com estudos realizados na Embrapa Clima Temperado (2008), ocorre uma grande variação de temperatura entre o dia e a noite em algumas regiões no Sul do Brasil, geralmente maior que $10^{\circ} \mathrm{C}$, principalmente nos períodos de primavera e outono. A amplitude térmica, associada às baixas temperaturas, é importante para conferir coloração e para o equilíbrio de acidez e açúcar, que é um fator determinante para o sabor do fruto consumido in natura.

Mota (2006a) relata valores de umidade na amora-preta cultivares Tupy e Guarani, de 91,7 e 90,47\%, respectivamente. Chim (2008) relata para as mesmas cultivares, respectivamente, $88,3 \%$ e $87,0 \%$. Pode-se observar que pelos estudos de Chim (2008), o teor de umidade de duas das cultivares foi inferior, demonstrando a variabilidade da constituição química de frutas de diferentes regiões.

A amora-preta in natura é altamente nutritiva, fazendo parte de sua composição a água (87-93\%), proteínas $(1,5 \%)$, fibras $(3,5-4,7 \%)$, cinzas $(0,19$ $-0,47 \%)$, lipídeos $(0,03-0,08 \%)$, carboidratos (6 - 13\%). Apresenta ainda conteúdos consideráveis (em $\mathrm{mg} / 100 \mathrm{~g}$ ) de cálcio (32); fósforo (21); potássio (196); magnésio $(20)$; ferro $(0,57)$; selênio $(0,60)$ e vitamina C (21); além de quantidades inferiores de vitamina A, vitamina E, folatos, tiamina, riboflavina, niacina, ácido pantotênico, vitaminas B-6 e B-12; ácidos graxos saturados; ácidos graxos monoinsaturados; e de ácidos graxos polinsaturados. No entanto, este fruto apresenta apenas cerca de 50-55 calorias em 100 gramas (Embrapa Clima Temperado, 2008).
O consumo regular desta fruta, aliado a um estilo de vida saudável, incluindo dieta equilibrada e exercícios físicos, pode prevenir alguns tipos de doenças crônicas não-transmissíveis. Além disto, alguns compostos encontrados nesta fruta, como as antocianinas, podem ser utilizados na indústria alimentícia como corante natural, seguindo a tendência mundial de redução no uso de corantes artificiais. A purificação e concentração de alguns fitoquímicos da amora-preta, como o ácido elágico, podem ser apresentados na forma de encapsulados, e comercializados como nutracêuticos (Embrapa Clima Temperado 2008).

O processamento das frutas da amoreira-preta, em produtos como geléias, sucos, iogurtes e sorvetes, é uma forma de agregar valor ao produto "in natura", auxiliando na renda dos fruticultores. No entanto, após o processamento podem ocorrer alterações das características funcionais originais das frutas, mas o impacto do processamento sobre as propriedades funcionais da amora-preta ainda está sendo estudado. Existem alguns estudos que relatam estas alterações, como os de Jacques (2009); Chim (2008) e Mota (2006b); os quais avaliaram a estabilidade de alguns dos principais fitoquímicos da amora-preta em produtos como polpa, geléia e suco respectivamente. No entanto, sabe-se que frutas e hortaliças respondem de forma diferenciada ao processo de transformação.

\section{Fitoquímicos}

A promoção da saúde como qualidade de vida e a busca por uma alimentação saudável têm sido metas a serem alcançadas neste século. Trabalhos envolvendo a atividade antioxidante de alimentos e substâncias isoladas de fontes naturais demonstram que o consumo de frutas, vegetais, vinhos e chás, estão relacionados à redução de risco de câncer e de doenças cardiovasculares (AJILA et al., 2007). De acordo com Speirs e Brady (1991), o amadurecimento de frutas envolve uma série de complexas reações bioquímicas, como a hidrólise do 
amido, a produção de carotenóides, de antocianinas e de compostos fenólicos, além da formação de vários compostos voláteis.

Publicações recentes relatam as propriedades de vários fitoquímicos com ação antioxidante, destacando-se os compostos fenólicos, os tocoferóis, o ácido ascórbico e os carotenóides, todos estes presentes na amora-preta. Esta fruta apresenta atividade antioxidante frente aos radicais superóxidos $\left(\mathrm{O}_{2} \bullet-\right)$, peróxido de hidrogênio $\left(\mathrm{H}_{2} \mathrm{O}_{2}\right)$, hidroxila $(\mathrm{OH} \bullet)$ e ao oxigênio singlete $\left(\mathrm{O}_{2}\right)$ (Wang e Jiao, 2000). Os valores que expressam a atividade antioxidante variam de acordo com o método utilizado. Em estudos in vitro, extratos de amorapreta apresentaram efeito antioxidante como "scavenger" do radical peroxinitrito, protegendo estas células de disfunções e falhas vasculares induzidas por este radical (SERRAINO et al., 2003).

Extratos de amora-preta têm apresentado efeito anti-mutagênico (TATE et al., 2006) e anticarcinogênico em linhagens humanas de câncer de útero, câncer de cólon (LAZZE et al., 2004), câncer oral, câncer de mama, câncer de próstata (SEERAM et al., 2006) e câncer de pulmão (DING et al., 2006). Segundo Tate et al. (2004), extratos de amora-preta podem prevenir a formação de metastase. Em muitos casos o efeito anti-carcinogênico da amorapreta ocorre devido ao efeito anti-inflamatório de seus extratos. Demonstrou-se que a capacidade antioxidante do plasma aumenta em 30\% após a ingestão de suco contendo amora-preta (NETZEL et al., 2002).

O efeito antioxidante demonstrado in vivo é de grande importância para incentivar o consumo destas frutas. Em ratos, antocianinas extraídas de amora-preta foram capazes de reduzir o número e o tamanho de tumores (câncer de pele) malignos e não malignos, os quais foram induzidos quimicamente na pele destes animais. Estes compostos inibiram a migração e invasão do câncer (DING et al., 2006).

Dentre os fitoquímicos presentes em frutos de amora-preta, os compostos fenólicos merecem destaque, devido à sua atividade antioxidante. A capacidade de inativação dos radicais livres pelos compostos fenólicos vem sendo atribuída à presença de grupamentos hidroxilas $(\mathrm{OH}-)$, que possuem capacidade de se ligar a radicais livres presentes no organismo, impedindo sua ação, que pode causar danos e/ou oxidação de componentes celulares (SEVERO et al., 2009).

\section{Compostos fenólicos}

Os compostos fenólicos são originados do metabolismo secundário das plantas, sendo essenciais para o seu crescimento e reprodução, além disso, se formam em condições de estresse como, infecções, ferimentos, radiações UV, dentre outros (NACZK; SHAHIDI, 2004). Os compostos fenólicos são incluídos na categoria de interruptores de radicais livres, sendo muito eficientes na prevenção da autoxidação (SHAHIDI; JANITHA; WANASUNDARA, 1992). Os compostos fenólicos presentes nas fontes vegetais são classificados como flavonóides e não flavonóides.

Os flavonóides são os compostos que apresentam a estrutura química básica como $\mathrm{C}_{6}-\mathrm{C}_{3}-\mathrm{C}_{6}$ (Figura 1). A presença e distribuição dos flavonóides nos vegetais depende de diversos fatores, como ordem e família do vegetal, bem como da variação das espécies. Os flavonóides são formados a partir da combinação de derivados sintetizados da fenilalanina (via metabólica do ácido chiquímico) e ácido acético (DEGÁSPARI; WASZCZYNSKY, 2004).

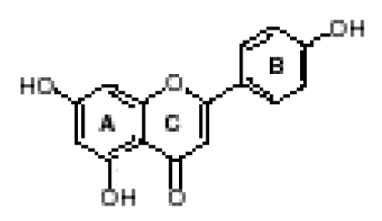

Figura 1. Estrutura básica dos flavanóides. Fonte: Skerget et al. (2005). 
Os padrões de distribuição dependem do grau de acesso à luminosidade, especialmente dos raios ultravioleta, pois a formação dos flavonóides é acelerada pela luz. O frio é um fator importante durante o período de dormência, para proporcionar índices adequados de brotação. No entanto, se as plantas forem submetidas ao frio fora dessa fase, pode causar sérios danos às gemas, flores e frutos em desenvolvimento, principalmente devido as geadas tardias de primavera (DEGÁSPARI; WASZCZYNSKY, 2004).

As antocianinas fazem parte do grupo dos flavonóides, que apresentam como características o núcleo básico flavílio (cátion 2-fenilbenzopirílio), o qual consiste de dois anéis aromáticos unidos por uma unidade de três carbonos, que são condensados por um oxigênio. A molécula de antocianina (Figura 2) é constituída por duas ou três porções, uma aglicona (antocianidina), um grupo de açúcares e, freqüentemente, um grupo de ácido orgânico (FRANCIS, 1989). As antocianinas possuem uma estrutura química adequada para a ação antioxidante, sendo capaz de doar elétrons ou átomos de hidrogênio para radicais livres (PRIOR, 2003).
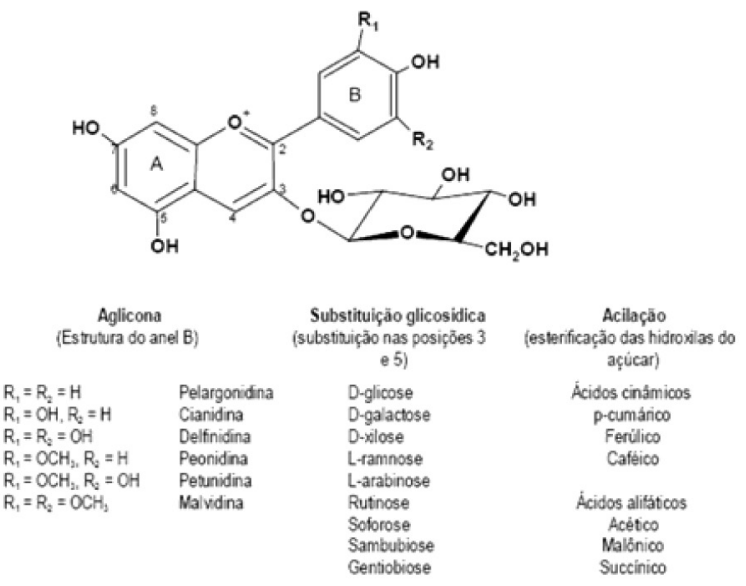

Figura 2. Estrutura geral da molécula de antocianina

Aproximadamente 22 agliconas são conhecidas, das quais 18 ocorrem naturalmente e apenas seis (pelargonidina, cianidina, delfinidina, peonidina, petunidina e malvidina) são importantes em alimentos (FRANCIS, 2000). Antocianidinas livres são raramente encontradas em plantas, ocorrendo comumente glicosiladas com açúcares que estabilizam a molécula (FRANCIS, 2000). A glicosilação pode ocorrer em várias posições, sendo observada com maior freqüência na posição 3 do anel aromático.

A quantidade de antocianinas na amora-preta varia em de acordo com o estádio de maturação das frutas. Estudos demonstram que seu conteúdo aumenta de 74,7 mg equivalente de cianidina-3glicosídeo/100 g peso fresco em frutos ainda verdes para $317 \mathrm{mg}$ cianidina-3-glicosídeo /100 g peso fresco em frutos sobremaduros (SIRIWOHARN; WROLSTAD, 2004). De acordo com Sellappan, Akoh e Krewer (2002), a variação no conteúdo de antocianinas entre cultivares pode ser bem acentuada, podendo variar de 12,70 a 197,34 mg.100 $\mathrm{g}^{-1}$ fruta. Estudos realizados por Wang e Lin (2000) com frutos de amora-preta, framboesa e morango, indicaram que os frutos maduros de framboesa preta e de amora-preta, constituem fontes ricas em antocianinas $\left(197,2 \mathrm{mg} .100 \mathrm{~g}^{-1}\right.$ fruta e $152,8 \mathrm{mg} .100 \mathrm{~g}^{-1}$ fruta, respectivamente) quando 
comparados com frutos maduros de framboesa vermelha (68,0 mg.100 g ${ }^{-1}$ fruta) e de morango (31,9 $\mathrm{mg} .100 \mathrm{~g}^{-1}$ fruta). Salienta-se que estas frutas, assim como a amora-preta, pertencem à família botânica das Rosáceas.

Estudos realizados por Jacques (2009), relatam teores de antocianinas totais na amora-preta cultivar Tupy na faixa de 140,73 mg cianidina-3glicosídio. $100 \mathrm{~g}^{-1}$ fruta, valores muito similares aos relatados por Chim (2008), de 137,59 mg cianidina3-glicosídio.100g-1 fruta. Ambas as frutas foram oriundas da região de Pelotas/RS/Brasil, porém de safras diferentes. Os valores de antocianinas totais relatados para amora-preta cultivar Tupy cultivada na cidade Poços de Caldas/MG/Brasil, foram pouco inferiores, 116,76 mg cianidina-3-glicosídio.100g${ }^{1}$ fruta, demonstrando a variabilidade em função do local de plantio.

Dentre as antocianinas identificadas em amora-preta, incluem-se a cianidina-3-glicosídeo (SERRAINO et al., 2003), cianidina-3-arabinosídeo, cianidina-3-galactosídeo, malvidina-3-glicosídeo, pelargonidina-3-glicosídeo, cianidina-3-xilosídeo, cianidina-3-rutinosídeo, cianidina-malonoil glicosídeo (FAN-CHIANG; WROLSTAD, 2005), cianidina-dioxaloil-glicosídeo, peonidina-3glicosídeo (SEERAM et al., 2006) e malvidinaacetilglicosídeo (REYES-CARMONA et al., 2005). Em termos quantitativos, $80 \%$ do total das antocianinas são na forma de cianidina-3-glicosídeo (SERRAINO et al., 2003).

Estudos tem demonstrado que o processamento, de forma geral, induz a redução no teor inicial de antocianinas. Em amora-preta é utilizada para a elaboração de geléia, foi observado uma perda de antocianinas em média de 8,8\% em relação aos valores encontrados na polpa. O armazenamento à temperatura ambiente das geléias em recipientes de vidros transparentes resultou em perdas de $32 \%$ do conteúdo de antocianinas nos primeiros 40 dias de estocagem e outros $11 \%$ nos 50 dias subseqüentes (MOTA, 2006b). Estudos realizados em suco de amora-preta, reforçam a idéia de que as antocianinas sofrem redução pós processamento. Mota (2006a) demonstrou que ocorreu uma redução de $42 \%$ do teor inicial de antocianinas através da elaboração de um suco por extração através de vapor.

O conteúdo de antocianinas em suco de amora também é influenciado pelo tempo e temperatura de armazenamento. Estudos com elaboração de suco e armazenamento por dois com relação ao teor inicial (PLADA et al., 2008).

Com base nos valores relatados na literatura sobre o conteúdo de antocianinas, e a grande variação entre os diferentes materiais genéticos, existe um grande potencial na produção de amorapreta visando a obtenção de corante natural para a indústria alimentícia e de medicamentos (Embrapa Clima Temperado, 2008).

Os compostos presentes nos extratos de amorapreta são absorvidos, metabolizados e distribuídos nos tecidos quando da sua ingestão. Estudos demonstram que as antocianinas são rapidamente absorvidas pelo intestino delgado, e após, são metabolizadas e excretadas na bile e urina na forma intacta, metiladas e/ou glicuronizadas (TALAVERA et al., 2004). Em ratos, estes compostos podem ser encontrados nos tecidos do estômago, jejuno, fígado, rins, cérebro e plasma (TALAVERA et al., 2005). Nos humanos, estes compostos são encontrados na urina, tanto na forma intacta, quanto em alguns metabolitos metilados, glicuronizados, sulfoconjugados, e aglícones (FELGINES et al., 2005).

Os compostos não flavonóides incluem (MELO; GUERRA, 2002):

a) Derivados das estruturas químicas $\mathrm{C}_{6}-\mathrm{C}_{1}$, incluindo os compostos hidroxibenzóicos, como os representados pelos ácidos p-hidroxibenzóico, gálico e elágico (Figura 3). 


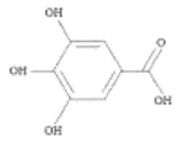

(a)

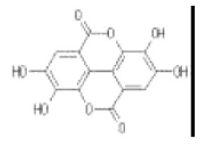

(b)

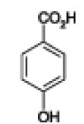

(c)
Figura 3. Estrutura química do ácido gálico (a), ácido elágico (b) e ácido p-hidróxibenzóico (c)

Fonte: Malacrida e Motta, 2006.

b) Derivados das estruturas químicas $\mathrm{C}_{6}-\mathrm{C}_{3}$, incluindo os compostos hidroxicinâmicos, representados pelos ácidos caféico e p-cumárico (Figura 4).

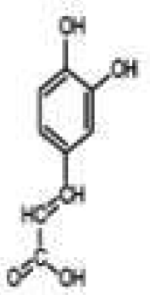

(a)

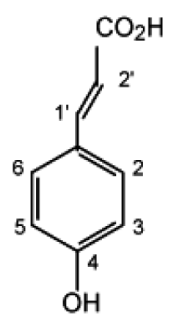

(b)
Figura 4. Estrutura química do ácido caféico (a) e do ácido p-cumárico (b)

Fonte: Filho, Pereira e Bayma, 2005.

c) Derivados das estruturas químicas $\mathrm{C}_{6}-\mathrm{C}_{2}-\mathrm{C}_{6}$, que são específicas do trans- e do cis- resveratrol (Figura 5).

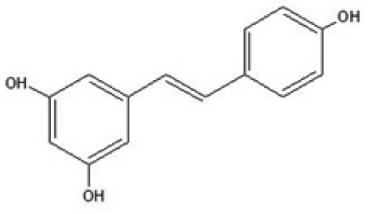

(a)

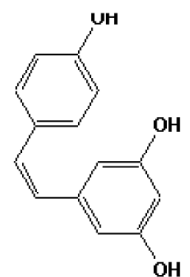

(b)
Figura 5. Estrutura química do trans resveratrol (a) e do cis-resveratrol (b)

Fonte: Filho, Pereira e Bayma, 2005
A atividade antioxidante dos não-flavonóides está relacionada com a posição dos grupos hidroxilas e também com a proximidade do grupo $-\mathrm{CO}_{2} \mathrm{H}$ com o grupo fenil. Quanto mais próximo esse grupo estiver do grupo fenil maior será a capacidade antioxidante do grupo hidroxila na posição meta. Em geral, a atividade antioxidante dos derivados dos ácidos hidrocinâmicos é maior do que a dos ácidos hidrobenzóicos. A presença do grupo $-\mathrm{CH}=\mathrm{CH}-\mathrm{COOH}$ na estrutura do ácido cinâmico aumenta sua capacidade de estabilizar radicais livres. Provavelmente, há conjugação da dupla ligação do grupo $-\mathrm{CH}=\mathrm{CH}-\mathrm{COOH}$ com as duplas do anel. Deve-se destacar que o ácido gálico apresenta atividade antioxidante maior do que a catequina (flavonóide), que conta com cinco grupos hidroxilas em sua estrutura (RICE-EVANS et al., 1996). A atividade antioxidante do ácido caféico é próxima a do ácido m-cinâmico, apesar de apresentar a mais um grupo hidroxila. Esse grupo na posição para do ácido p-cumárico lhe proporciona maior atividade antioxidante quando comparado com o ácido hidrocinâmico.

Relatos da literatura demonstram uma variabilidade no conteúdo de compostos fenólicos totais em amora-preta de 261,95 a 929,62 mg equivalente de ácido gálico. $100 \mathrm{~g}^{-1} \mathrm{de}$ fruta fresca (Embrapa Clima Temperado, 2008), 569,89mg ác. gálico.100 $\mathrm{g}^{-1}$ fruta (CHIM, 2008), até 1938,70 $\mathrm{mg}$ ácido galico.100 $\mathrm{g}^{-1}$ fruta (JACQUES, 2009). Esta variabiliade no conteúdo de fenóis pode estar relacionado a diferença de metodologias empregadas na extração da amostra para a determinação dos fenóis totais, pela diferença de safra, clima ou pela localização das plantas.

Comparando a amora-preta com outras frutas da mesma família botânica, como a framboesa $(30 \mathrm{mg}$ ácido galico. $100 \mathrm{~g}^{-1}$ fruta) e morango ( $80 \mathrm{mg}$ ácido galico.100 g-1 fruta) (AGAR; STREIF; BANGERTH, 1997), observa-se que a amora-preta compreende maior conteúdo de compostos fenólicos totais. 
Estudos anteriores encontraram na amora-preta os seguintes compostos fenólicos da classe dos não flavonóides: ácido gálico, ácido hidroxibenzóico, cafeico, cumárico, ferúlico, elágico (SELLAPPAN; AKOH; KREWER, 2002). De acordo com Siriwoharn e Wrolstad (2004), além dos ácidos gálico, elágico encontrados por Sellappan, Akoh e Krewer (2002) foram identificados também a quercetina e kampferol. Jacques (2009), identificou o ácido elágico e o kampferol. Estas diferenças na constituição dos compostos fenólicos podem ocorrer pela diferenciação de espécie e cultivar, já que os primeiros autores utilizaram amora Marion (Rubus sp. hyb) e Evergreen (Rubus laciniatus), e a amora-preta avaliada no estudo de Jacques (2009), foi a da espécie Rubus fruticosus.

Estudos realizados por Jacques (2009) relatam que o ácido gálico foi o ácido fenólico predominante na amora-preta cultivar Tupy, compreendendo 64\% do total dos ácidos fenólicos identificados. Estes dados estão de acordo com os resultados reportados por Chim (2008), que também descreve o ácido gálico como sendo o ácido fenólico predominante, com cerca de $60 \%$ dos ácidos fenólicos identificados. Estes resultados confirmam dados da literatura que reportam o ácido gálico como sendo o ácido fenólico de maior expressão dentre os compostos fenólicos identificados em amora-preta (SINGLETON; ROSSI, 1996).

De acordo com estudos de estabilidade de compostos fenólicos na amora-preta frente ao armazenamento congelado realizado por Jacques (2009), observou-se que o ácido gálico apresentou uma das maiores taxas de degradação dentre os compostos fenólicos individuais, talvez pela associação com sua estrutura altamente hidroxilada, que favorece maior disponibilidade para reações de oxi-redução.

\section{Ácido Ascórbico}

A vitamina $\mathrm{C}$, ou ácido L-ascórbico (AA), é uma vitamina hidrossolúvel e termolábil. O
AA é amplamente distribuído nos vegetais e em produtos de origem vegetal, sendo encontrado, principalmente, em frutas cítricas e hortaliças folhosas (ZHANG; HAMAUZU, 2004).

O AA encontra-se na natureza sob a forma reduzida, denominada de ácido L-ascórbico, ou na forma de ácido L-dehidroascórbico (DHA), que consiste no produto primário do processo de oxidação do anel lactona do ácido L-ascórbico; porém, a forma oxidada apresenta-se em menores quantidades nos compostos naturais. A transformação do AA em DHA ocorre normalmente no interior do organismo, e como é reversível, permite que uma destas formas possa ser transformada na outra (Figura 6). Essa capacidade de conversão atua como um sistema oxido-redutor, que é capaz de transportar hidrogênio no processo de respiração ao nível celular (WELCH et al., 1995; TAVARES et al., 2000).

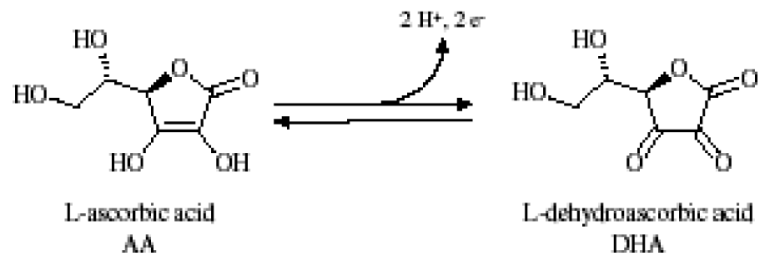

Figura 6. Oxi-redução do ácido L-ascórbico Fonte: Silva, Lopes e Valente-Mesquita, 2006.

O ácido L-dehidroascórbico (DHA) também apresenta atividade vitamínica, pois é facilmente reduzido no organismo, e apresenta cerca de $80 \%$ da atividade vitamínica do AA. A atividade antioxidante da vitamina $\mathrm{C}$ envolve a doação de um elétron e a formação do radical livre ascorbato (ROSA et al., 2007).

O teor de vitaminas nas frutas pode variar dependendo da espécie, do estádio de maturação na época da colheita, de variações genéticas, do manuseio pós-colheita, das condições de estocagem e do processamento (SILVA; LOPES; VALENTE-MESQUITA, 2006). De acordo com Wang e Lin (2000) existem poucas informações sobre a capacidade anti-oxidante de frutos em 
diferentes estádios de desenvolvimento. Esses autores observaram que em estádios de maturação mais avançados de alguns frutos, tais como amora, morango e framboesa, ocorre um aumento na capacidade anti-oxidante destes frutos. Apesar desse aspecto nutricional relevante relacionando grau de maturação e propriedades anti-oxidantes, normalmente o estádio de maturidade do fruto é baseado apenas na avaliação da cor superficial dos frutos (WANG; LIN, 2000).

De acordo com Jacques (2009), o conteúdo de ácido ascórbico presente na amora-preta $(0,9$ $\mathrm{mg}$ ácido ascórbico. $100 \mathrm{~g}^{-1}$ fruta) é baixo quando comparado com outras frutas estudados por Hernandéz, Lobo e Gonzáles (2006) e Araújo et al. (2007), como do conteúdo no mamão papaya (86,0 mg ácido ascórbico. $100 \mathrm{~g}^{-1}$ fruta), na manga (89,0 mg ácido ascórbico. $100 \mathrm{~g}^{-1}$ fruta) e na acerola (183mg.100g $\mathrm{g}^{-1}$ ). Chim (2008), relata teores de 2,4 $\mathrm{mg}$ ácido ascórbico. $100 \mathrm{~g}^{-1}$ fruta na amora-preta $\mathrm{cv}$. Tupy, resultado superior ao encontrado no estudo de Jacques (2009).

Estudos realizados por Pantelidis et al. (2007), relatam grandes variações nos teores de vitamina $\mathrm{C}$ em diversas cultivares de amora-preta e framboesa, ambas da familia botânica Rosaceae e gênero Rubus, na faixa de 14,3 à 103,3 mg ácido ascórbico. $100 \mathrm{~g}^{-1}$ fruta fresca.

Chim (2008), concluiu em seu estudo que frutos de amora-preta possuem teores de vitamina $\mathrm{C}$ pouco expressivos. Apesar de ser considerado um fruto rico em compostos com ação antioxidante, a amora-preta não seria indicada como única fonte para suprir as necessidades diárias de vitamina $\mathrm{C}$.

No processamento da amora-preta na forma de polpa, não se observou degradação da vitamina C, na forma de ácido L-ascórbico (0,9 mg ácido ascórbico. $100 \mathrm{~g}^{-1}$ fruta), além de não apresentar diferença ao nível de 5\% de significância após 4 meses de armazenamento nas temperaturas de $-10 \mathrm{e}$ $-18^{\circ} \mathrm{C}$. No entanto, aos 6 meses de armazenamento, observou-se a degradação total dessa vitamina, inclusive na polpa armazenada a $-18^{\circ} \mathrm{C}$ (Jacques 2009).

\section{Tocoferóis}

A vitamina $E$ consiste na denominação genérica de oito compostos lipossolúveis, o alfa $(\alpha)$, beta $(\beta)$, gama $(\gamma$.) e delta $(\delta)$ - tocoferóis, alem do $\alpha, \beta, \gamma$. e $\delta$ - tocotrienóis, cada um com atividades biológicas específicas; porém, o $\alpha$ - tocoferol é o composto que apresenta maior atividade como antioxidante (BIANCHINI; PENTEADO, 2003; BALL, 1998).

Os tocoferóis (Figura 7) ocorrem naturalmente em praticamente todos os vegetais, principalmente nos vegetais verde-escuros, nas sementes oleaginosas, nos óleos vegetais e no germem de trigo. Os tocotrienóis são encontrados apenas em um pequeno grupo de vegetais, como em algumas variedades de palma. A ocorrência natural dos diferentes compostos que fazem parte da vitamina $\mathrm{E}$ diferenciam-se entre os vegetais, mas o $\alpha$ - tocoferol tem ocorrência mais comum (SETIADIA, 2003).

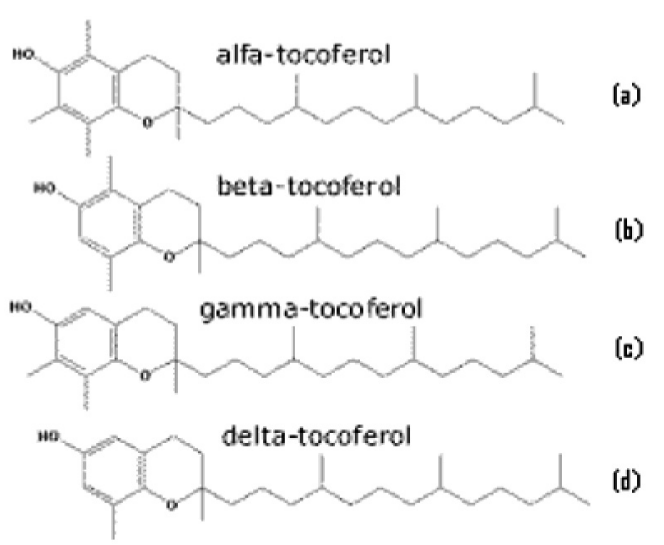

Figura 7. $\alpha$-tocoferol (a); $\beta$-tocoferol (b); $\gamma$-tocoferol (c); e $\delta$ - tocoferol (d).

Fonte: Vitamina E, 2005.

A rota da vitamina $\mathrm{E}$ no organismo segue o caminho geral de um antioxidante lipídico na estabilização de membranas subcelulares, mas se tem observado que estes compostos participam também de outras atividades vitamínicas (DÍAZ, 
2007; SIQUEIRA; 1997). A função da vitamina E como antioxidante na peroxidação das membranas celulares ocorre pelo fornecimento de um átomo de hidrogênio ao radical peróxido formado, agindo como seqüestrante de radicais livres, protegendo assim as membranas celulares de possíveis danos (SIQUEIRA, 1997).

A vitamina E apresenta pouca resistência ao aquecimento e à ação de ácidos, sendo instável na presença de agentes alcalinos, da luz ultravioleta e do oxigênio. Essa vitamina é destruída quando em contato com gorduras rançosas, e com os metais chumbo e ferro. Como são insolúveis em água, não há perda por lixiviação durante o processo de cocção (RICE-EVANS; MILLER, 1995).

A vitamina E é encontrada principalmente em produtos que apresentam alto teor em gordura, como amêndoas, óleos vegetais e algumas frutas e vegetais (LINS, 2006). A amora-preta apresenta quantidades muito pequenas de tocoferóis $(0,870$ $\mathrm{mg}$ tocoferol.100 $\mathrm{g}^{-1}$ fruta fresca), o que pode ser explicado pela baixa quantidade de gordura presente nesta fruta (JACQUES, 2009).

De acordo com Chim (2008), as cultivares de amora-preta Guarani e Brazos apresentam quantidades de tocoferóis semelhantes $(0,468 \mathrm{mg}$ tocoferol. $100 \mathrm{~g}^{-1}$ fruta $0,537 \mathrm{mg}$ tocoferol. $100 \mathrm{~g}^{-1}$ fruta, respectivamente); porém, apresentam quantidades inferiores aos dados relatados por Chun et al. (2006) para a amora-preta $\left(1,43 \mathrm{mg}\right.$ tocoferol.100 $\mathrm{g}^{-1}$ fruta).

Os dados de quantificação de tocoferóis em amora-preta são escassos, porém comparando o conteúdo de tocoferóis na amora-preta cultivar Tupy (0,87 mg.100 $\left.\mathrm{g}^{-1}\right)$ (Jacques, 2009), observa-se uma similaridade com o conteúdo de outras frutas, como no figo $\left(0,76 \mathrm{mg}\right.$ tocoferol. $100 \mathrm{~g}^{-1}$ fruta $)$, nectarina $\left(0,73 \mathrm{mg}\right.$ tocoferol. $100 \mathrm{~g}^{-1}$ fruta) e mirtilo $(1,05 \mathrm{mg}$ tocoferol.100 $\mathrm{g}^{-1}$ fruta) (CHUN et al., 2006), e no tomate $\left(0,89 \mathrm{mg}\right.$ tocoferol. $100 \mathrm{~g}^{-1}$ fruta) (LEE et al., 2000).

\section{Carotenóides}

Os carotenóides constituem um dos mais importantes grupos de pigmentos na natureza, devido às suas numerosas funções, larga distribuição e diversidade estrutural (OLIVER; PALOU, 2000). Uma das suas principais funções é a atividade provitamínica $\mathrm{A}$. A vitamina A é essencial para a diferenciação celular, para a visão, para o crescimento ósseo, na reprodução e na integração do sistema imunológico, sendo que sua deficiência pode resultar em anemia (LAYRISSE, 2000).

Os carotenóides compreendem uma família de compostos naturais, dos quais mais de 600 variantes estruturais estão reportadas e caracterizadas, a partir de bactérias, algas, fungos e plantas superiores (FONTANA et al., 1997). A estrutura química dos carotenóides é baseada em uma cadeia de carbonos com a presença de ligações duplas, compartilhadas ou não. Estas ligações duplas características fazem desses compostos potenciais antioxidantes, uma vez que suas moléculas são capazes de receber elétrons de espécies reativas, neutralizando os radicais livres.

Estes compostos constituem-se em pigmentos comumente presentes em alimentos de origem vegetal, sendo responsáveis pelas colorações amarela, alaranjada e vermelha. Os carotenóides também ocorrem em vegetais folhosos, que na sua grande maioria são verdes devido a presença da clorofila, que é o pigmento predominante (CTENAS; VITOLO, 2000).

$\mathrm{Na}$ amora-preta, devido ao elevado conteúdo de antocianinas totais, a coloração amarelada característica da presença de carotenos não é representativa como em outras frutas.O conteúdo de carotenóides totais em amora-preta $(0,877 \mathrm{mg}$ $\beta$-caroteno. $100 \mathrm{~g}^{-1}$ de fruta) é reportado como sendo superior ao da acerola $\left(0,53 \mathrm{mg}\right.$ de $\beta$-caroteno. $100 \mathrm{~g}^{-1}$ de fruta) que, assim como a amora-preta tem uma predominância de antocianinas (ARAÚJO et al., 2007). 
De acordo com Marinova e Ribarova (2007), a amora-preta apresenta vários carotenóides, incluindo a luteína $\left(0,3 \mathrm{mg} \cdot 100 \mathrm{~g}^{-1}\right.$ de fruta), zeaxantina (29,0 mg.100 $\mathrm{g}^{-1}$ de fruta), $\beta$-criptoxanthina $(30,1$ mg. $100 \mathrm{~g}^{-1}$ de fruta), $\alpha$-Caroteno $\left(9,2 \mathrm{mg} .100 \mathrm{~g}^{-1}\right.$ de fruta) e $\beta$-caroteno (101,4 mg. $100 \mathrm{~g}^{-1}$ de fruta). Jacques (2009) relata a presença em amora-preta cv. Tupy de $\beta$-criptoxantina $\left(0,227 \mathrm{mg} .100 \mathrm{~g}^{-1}\right.$ de fruta), luteína+zeaxantina $\left(0,519 \mathrm{mg} \cdot 100 \mathrm{~g}^{-1}\right.$ de fruta) , $\beta$-caroteno ( $0,003 \mathrm{mg} .100 \mathrm{~g}^{-1}$ de fruta) e licopeno (0,015 mg. $100 \mathrm{~g}^{-1}$ de fruta).

\section{Considerações Finais}

Através desta revisão, percebe-se uma crescente conscientização de que a inclusão de frutas como a amora-preta, seja na forma in natura ou processadas como sucos, geléias e sorvetes, no hábito alimentar, tem efeito benéfico sobre a saúde das pessoas, acarretando numa forte tendência de aumento do consumo em quase todo o mundo. Assim a indústria atenta às exigências e tendências do mercado, vem cada vez mais buscando alternativas e formas de processamento, a fim de oferecerem um produto saudável, de boa apresentação, preservando com integridade suas propriedades nutricionais.

A amoreira-preta possui grandes possibilidades de atingir o mercado destinado a frutas de mesa, principalmente realçando a ausência da utilização de agroquímicos na fase de produção e qualidades intrínsecas ao fruto como a presença de ácido elágico. Entre os antioxidantes presentes na amora-preta, os mais ativos e freqüentemente encontrados são os compostos fenólicos, tais como os flavonóides. As propriedades benéficas desses compostos podem ser atribuídas à sua capacidade de seqüestrar os radicais livres. Além dos compostos fenólicos, outros componentes possuem atividade antioxidante, estão todos presentes na amora-preta, como: as vitaminas $\mathrm{C}$ e E e os carotenóides.

\section{Referências}

AGAR, I. T.; STREIF, J.; BANGERTH, F. Effect of high $\mathrm{CO} 2$ and controlled atmosphere (CA) on the ascorbic and dehydroascorbic acid content of some berry fruits. Postharvest Biology and Technology, Amsterdan, v. 11, n. 1, p. 47-55, 1997.

AJILA, C. M.; NAIDU, K. A.; BHAT, S. G.; PRASADA RAO, U. J. S. Bioactive compounds and antioxidant potential of mango peel extract. Food Chem., London, v. 105, n. 3, p. 982, 2007.

ANTUNES, L. E. Amora-preta: nova opção de cultivo no Brasil. Ciência Rural, Santa Maria, v. 32, n. 1, p. 151158, 2002.

ANTUNES, L. E.; RASEIRA, M. C. B. Aspectos técnicos da cultura da amora-preta. Pelotas: Embrapa Clima Temperado, 2004. 54 p. (Embrapa Clima Temperado. Documentos, 122).

ARAÚJO, P. G. L.; FIGUEIREDO, R. W.; ALVES, R. E.; MAIA, G. A.; PAIVA, J. R. $\beta$-caroteno, ácido ascórbico e antocianinas totais em polpa de frutos de aceroleira conservada por congelamento durante 12 meses. Ciênc. e Tec. de Aliment., Campinas, v. 27, n. 1, p. 104-107, 2007.

AZEVEDO-MELEIRO, C. H.; RODRIGUEZ-AMAYA, D. B. Confirmation of the identity of the carotenoids of tropical fruits by HPLC-DAD and HPLC-MS. Jour. of Food Composition and Analysis, Orlando, v. 17, n. 3, p. 385-396, 2004.

BALL, G. F. M. Bioavailability and analysis of vitamin in foods. Chapman \& Hall: London, U.K. p. 195-239, 1998.

BIANCHINI, R.; PENTEADO, M. V. C. Vitamina E. Vitaminas: aspectos nutricionais, bioquímicos, clínicos e analíticos. Barueri: Manole, p. 23-164, 2003.

CHIM, J. F. Caracterização de compostos bioativos em amora-preta (Rubus sp.) e sua estabilidade no processo e armazenamento de geléias convencional e light. 2008. Tese (Doutorado em Ciência e Tecnologia Agroindustrial) - Faculdade de Agronomia. Universidade Federal de Pelotas, Pelotas.

CHUN, J.; LEE, J.;YE, LIN; EXLER, J.; EITENMILLER, R. R. Tocopherol and tocotrienol contents of raw and processed fruits and vegetables in the United States diet. Jour. of Food Composition and Analysis, Orlando, v. 19, n. 2/3, p. 196-204, 2006.

CTENAS, A.; VITOLO, M. R. Crescendo com saúde. São Paulo: C2 editora e consultoria em nutrição, 2000. Disponível em: <http://www.crescendocomsaude.com. br>. Acesso em: 09 out. 2008. 
DAUBENY, H. A. Brambles. In: JANICK, J. E.; MOORE, J. N. (Ed.). Fruit breeding. New York: John Wiley \& Sons, 1996. p. 109-190.

DEGÁSPARI, C. H.; WASZCZYNSKYJ, N. Propriedades antioxidantes de compostos fenólicos. Visão Acadêmica, Curitiba, v. 5, n. 1, p. 33-40, 2004.

DÍAZ, T. G. Chemonetrics for the resolution of coeluting peaks of $\beta$-and $\gamma$ - tocopherols in RP-HPLC: Determination in edible oils and dietary supplements. Food Chem., Spain, v. 105, n. 4, p. 1583-1590, 2007.

DING, M.; FENG, R.; WANG, S.Y.; BOWMAN, L.; LU, Y.; QIAN, Y.; CASTRANOVA, V.; JIANG, B-H.; SHI, $\mathrm{X}$. Cyanidin-3-glucoside, a Natural Product Derived from Blackberry, Exhibits Chemopreventive and Chemotherapeutic Activity. Jour. of Biological Chem., Maryland, v. 281, n. 25, p. 17359-17368, 2006.

EMPRESA BRASILEIRA DE PESQUISA AGROPECUÁRIA - EMBRAPA. Embrapa Clima Temperado Sistemas de Produção. Disponível em: $<$ http://www.embrapa.br>. Acesso em: 10 set. 2008.

FAN-CHIANG, H-J.; WROLSTAD, R. Anthocyanin pigment composition of blackberries. Jour. of Food Science, Chicago, v. 70, n. 3, p. 198-202, 2005.

FELGINES, C.; TALAVERA, S.; TEXIER, O.; GILIZQUIERDO, A.; LAMAISON, J-L.; REMESY, C. Blackberry anthocyanins are mainly recovered from urine as methylated and glucuronidated conjugates in humans. Jour. of Agricultural and Food Chem., Washington, v. 53, n. 20, p. 7721-7727, 2005.

FILHO, S.; PEREIRA, A. P. S.; BAYMA, J. C. Aleloquímico produzido pela gramínea forrageira Brachiaria humidicola. Planta Daninha, Londrina, v. 23, n. 1, p. 25-32, 2005.

FONTANA, J. D.; MENDES, S. V.; PERSIKE, D.S.; PERACETTA, L. F.; PASSOS, M. Carotenóides cores atraentes e ação biológica. $11^{\circ}$ prêmio paranaense em C\&T 1997. Disponível em: <http://www.herbario.com. br/dataherb06/1112carotenoid.htm $>$. Acesso em: 10 set. 2008.

FRANCIS, F. J. Food colorants: anthocyanins. Food Science and Nutrition, Amherst, v. 28, n. 4, p. 273-314. 1989.

Anthocyanins and betalains: composition and applications. Cereal Foods World, Chicago, v. 45, n. 5, p. 208-213, 2000.

HERNANDÉZ, Y.; LOBO, M. G.; GONZÁLES, M. Determination of vitamin $\mathrm{C}$ in tropical fruits: $\mathrm{A}$ comparative evaluation of methods. Food Chem., London, v. 96, n. 4, p. 654-664, 2006.
JACQUES, A. C. Estabilidade de compostos bioativos em polpa congelada de amora-preta (rubus fruticosus) cv.tupy. 2009. Tese (Mestrado em Ciência e Tecnologia Agroindustrial) - Faculdade de Agronomia. Universidade Federal de Pelotas, Pelotas.

KRINSKY, N. I. Carotenoids as chemopreventive agents. Preventive Medicine, San Diego, v. 18, n. 5, p. 592-602, 1989.

KUSKOSKI, E. M.; ASUERO, A. G.; TRONCOSO, A. M.; MANCINI-FILHO; FETT, R. Aplicación de diversos métodos químicos para determinar actividad antioxidante en pulpa de frutos. Ciênc. e Tec. Aliment., Campinas, v. 25, n. 4, p. 726-732, 2005.

LAYRISSE, M. New property of vitamin A and $\beta$-carotene on human iron absorption: effect on phytate and polyphenols as inhibitors of iron absorption. Arch. Latinoam. Nutr., Guatemala, v. 50, n. 3, p. 243-248, 2000.

LAZZE, M. C.; SAVIO, M.; PIZZALA, R.; CAZZALINI, O.; PERUCCA, P.; SCOVASSI, A. I.; STIVALA, L. A.; BIANCHI, L. Anthocyanins induce cell cycle perturbations and apoptosis in different human cell lines. Carcinogenesis, Oxford, v. 25, n. 8, p. 1427-1433, 2004.

LEE, J.; YE, L.; LANDEN, W. O.; EITENMILLER, R. R. Optimization of an extraction procedure for the quantification of vitamin e in tomato and broccoli using response surface methodology. Jour. of Food Composition and Analysis, Orlando, v.13, n. 1, p. 45-57, 2000.

LINS, R. T. Determinação de tocoferóis e carotenóides em frutas amazônicas: Implantação de uma metodologia. 2006. Dissertação (Mestrado em Ciência e Tecnologia de Alimentos) - Centro Tecnológico. Universidade Federal do Pará, Pará.

MAAS, J. L.; GALLETTA, G. J.; STONER, G. D. Ellagic acid, na anticarciogen in fruits, especially in strawberry: a review. HortScience, Alexandria, v. 26, n. 1, p. 10-14. 1991.

MALACRIDA, C. R.; MOTTA, S. da. Antocianinas em suco de uva: composição e estabilidade. B. Ceppa, Curitiba,v. 24, n. 1, p. 59-82, 2006.

MARINOVA, D.; RIBAROVA, F.; HPLC determination of carotenoids in Bulgarian berries. Journal of Food Composition and Analysis, v. 20, n. 5, p.370-374; 2007.

MELO, E. A.; GUERRA, N. B. Ação antioxidante de compostos fenólicos naturalmente presentes em alimentos. Ciênc. e Tec. de Aliment., Campinas, v. 36, n. 1, p. 1-11, 2002.

MOREIRA, A.V. B.; MANCINI-FILHO, J. Influência dos compostos fenólicos de especiarias sobre a lipoperoxidação e o perfil lipídico de tecidos de ratos. Rev. Nutr., Campinas, v. 17, n. 4, p. 411-240, 2004. 
MOTA, R. V. Caracterização do suco de amora-preta elaborado em extrator caseiro. Ciênc. Tecnol. Aliment., Campinas, v. 26, n. 2, p. 303-308, 2006a.

Caracterização física e química de geléia de amora-preta. Ciênc. e Tec. de Aliment., Campinas, v. 26, n. 3, p. 539-543, 2006 b.

NACZK, M.; SHAHIDI, F. Extraction and analysis of phenolics in food. Journal Chromat. A., Washington, v. 1054, n. 1/2, p. 95-111, 2004.

NACHTIGALL, A. M.; SOUZA, E. L. de; MALGARIM, M. B.; ZAMBIAZI, R. C. Geléias light de amora-preta. B. Ceppa, Curitiba, v. 22, n. 2, p. 337-354, 2004.

NETZEL, M.; STRASS, G.; KAUL, C.; BITSCH, I.; DIETRICH, H.; BITSCH, R. In vivo antioxidative capacity of a composite berry juice. Food Research International, Canada, v. 35, p. 213-216, 2002.

OLIVER, J.; PALOU, A. Chromatographic determination of carotenoids in foods. J. Chromatogr., Amsterdam, v. 881, n. 1, p. 543-555, 2000.

PANTELIDIS, G. E.; VASILAKAKIS, M.; MANGANARIS, G. A.; DIAMANTIDIS, G. Antioxidant capacity, phenol, anthocyanin and ascorbic acid contents in raspberries, blackberries, red currants, gooseberries and Cornelian cherries. Food Chem., Greece, v. 102, p. 777-783, 2007.

PLADA, G. M.; JACQUES, A. C.;.PERTUZATTI, P. B.; BARCIA, M. T.; ZAMBIAZI, R. C.

Conteúdo de fitoquímicos em suco de amora-preta (rubus spp.) armazenado sob diferentes temperaturas. In: CONGRESSO DE SEGURANÇA ALIMENTAR, 2., 2008, Bento Gonçalves. Anais... Bento Gonçalves: [s.n.], 2008.

POLING, E. B. Blackberries. Journal of Small Fruit and Viticulture, Baton Rouge, v. 14, n. 1/2, p. 38-69. 1996.

PRIOR, R. L. Fruits and vegetables in the prevention of cellular oxidative damage. Am J Clin Nutr., Arkansas, v. 78, n. 3, p. 570-578, 2003.

REYES-CARMONA, J.; YOUSEF, G. G.; MARTÍNEZPENICHE, R. A.; LILA, M. A. Antioxidant capacity of fruit extracts of blackberry (Rubus sp.) produced in different climatic regions. Jour. of Food Science, Chicago, v. 70, n. 7, p. 497-503, 2005.

RICE-EVANS, C.; MILLER, N. J. Antioxidants - the case for fruit and vegetables in the diet. British Food Journal, Bradford, v. 91, n. 9, p. 35-40, 1995.

RICE-EVANS， C.; NICOLAS， J.; MILLER， J.; PAGANGA, G. Structure-antioxidant activity relationships of flavonoids and phenolic acids. Free Radic. Biol. Med., London, v. 20, n. 3, p. 933-956, 1996.
ROSA, J. S.; GODOY, R. L. O.; NETO, J. O.; CAMPOS, R. S.; MATTA, V. M.; FREIRE, C. A.; SILVA, A. L.; SOUZA, R. S. Desenvolvimento de um método de análise de vitamina $\mathrm{C}$ em alimentos por cromatografia líquida de alta eficiência e exclusão iônica. Ciênc. e Tec. de Aliment.,Campinas, v. 27, n. 4, p. 837-846, 2007.

SANTOS, A. M.; RASEIRA, M. C. B.; MADAIL, J. C. M. A cultura da amora-preta. Brasília: Embrapa SPI, 1997. 61 p. (Coleção Plantar, 33).

SEERAM, N. P.; ADAMS, L. S.; ZHANG, Y.; LEE, R.; SAND, D.; SCHEULlER, H. S.; HEBER, D. Blackberry, black raspberry, blueberry, cranberry, red raspberry, and strawberry extracts inhibit growth and stimulate apoptosis of human cancer cells in vitro. Jour. of Agric. and Food Chem., Washington, v. 54, n. 25, p. 9329-9339, 2006.

SELLAPPAN, S.; AKOH, C. C.; KREWER, G. Phenolic compounds and antioxidant capacity of georgia-grown blueberries and blackberries. Journal of Agricultural and Food Chem., Washington, v. 50, n. 8, p. 2432-2438, 2002.

SERRAINO, I.; DUGO, L.; DUGO, P.; MONDELLO, L.; MAZZON, E.; DUGO, G.; CAPUTI, A. P.; CUZZOCREA, S. Protective effects of cyanidin-3-Oglucoside from blackberry extract against peroxynitriteinduced endothelial dysfunction and vascular failure. Life Sciences, Amsterdan. v. 73, p. 1097-1114, 2003.

SETIADIA, D. H. Vitamin E models. Shortened side chain models of $\mathrm{a}, \mathrm{b}, \mathrm{g}$ and $\mathrm{d}$ tocopherol and tocotrienol: a density functional study. Jour. Mol Struct., Amsterdam, v. 637, n. 1/3, p. 11-26, 2003.

SEVERO, J.; GALARÇA, S. P.; AIRES, R. F.; CANTILLANO, R. F. F.; ROMBALDI, C. V.; SILVA, J. A. Avaliação de compostos fenólicos, antocianinas, vitamina C e capacidade antioxidante em mirtilo armazenado em atmosfera controlada. Braz. Jour. Food Technol., Pelotas, II SSA, 2009. Edição Especial.

SHAHIDI, F.; JANITHA, P. K.; WANASUNDARA, P. D. Phenolic antioxidants. Rev. Food Science Nutr, Curitiba, v. 32, n. 1, p. 67-103, 1992.

SHAHIDI, F.; MARIAN, N. Phenolics in food and nutraceuticals. In: RABAH, T. M.; KHALIL, I. E.; HOWARD, L. Effect of ascorbic acid and dehydration on concentrations of total phenolics, antioxidant capacity, anthocyanins, and color in fruits. Jour. of Agric. and Food Chem., Davis, v. 53, n. 11, p. 4444-4447, 2003.

SILVA, P. T.; LOPES, M. L. M.; VALENTE-MESQUITA, V. L. Efeito de diferentes processamentos sobre o teor de Ácido ascórbico em suco de laranja utilizado na elaboração de bolo, pudim e geléia. Ciênc. e Tec. de Aliment., Campinas, v. 26, n. 3, p. 678-682, 2006. 
SINGLETON, V. L.; ROSSI, J. A. Colorimetry of total phenolics withphosphomolybdic phosphotungstic acid reagents. Am. J. Enol. Vitic.,California, v.16, n. 3, p. 144$158,1996$.

SIQUEIRA, F. M. Nutrientes antioxidantes. Ciênc. e Tec. Agro., Campinas, v. 31, n. 2, p. 192-199, 1997.

SIRIWOHARN, T.; WROLSTAD, R. E. Polyphenolic composition of marion and evergreen blackberries. Jour. of food Science, Davis, v. 69, n. 4, p. 233-240, 2004.

SKERGET, M.; KOTNIK, P.; HADOLIN, M.; HRAS, A. R., SIMONIC, M.; KNEZ, Z. Phenols, proanthocyaninas, flavones and flavonols in some plant materials and their antioxidant activities. Food Chem., Davis, v. 89, n. 4, p. 191-198, 2005.

SPEIRS, J.; BRADY, C. J. Modification of gene expression in ripening fruit. Australian Journal of Plant Physiology, Australian, v.18, p.519-532, 1991.

TALAVERA, S. V.; FELGINES, C.; TEXIER, O.; BESSON, C.; GIL-IZQUIERDO, A.; LAMAISON, J-L.; REMESY, C. Anthocyanin metabolism in rats and their distribution to digestive area, kidney, and brain. Jour. of Agr. and Food Chem., Washington, v. 53, n. 10, p. 39023908, 2005.

TATE, P.; GOD, J.; BIBB, R.; LU, Q.; LARCOM, L. L. Inhibition of metallo proteinase activity by fruit extracts. Cancer Letters, Oxford, v. 212, n. 2, p. 153-158, 2004.

TATE, P.; STANNER, A.; SHIELDS, K.; SMITH, S.; LARCOM, L. Blackberry extracts inhibit UV-induced mutagenesis in Salmonella typhimurium TA100. Nutr. Research, Amsterdan, v. 26, p. 100-104, 2006.
TAVARES, J. T. Q.; SILVA, C. L.; CARVALHO, L. A.; SILVA, M. A.; SANTOS, C. M. G. Estabilidade do ácido ascórbico em suco de laranja submetido a diferentes tratamentos. Magistra, Cruz das Almas, v. 12, n. 1/2, jan./dez. 2000.

WANG, S. Y.; LIN, H. S. Antioxidant activity in fruits and leaves of blackberry, raspberry and strawberry varies with cultivar and developmental stage. Jour.of Agric. Food Chem., Washington, v. 48, n. 2, p. 140-146, 2000.

WANG, S.Y.; JIAO, H. Scavenging capacity of berry crops on superoxide radicals, hydrogen peroxide, hydroxyl radicals, and singlet oxygen. Jour. of Agr. and Food Chem., Washington, v. 48, n. 11, p. 5677-5684, 2000.

WANG, S. Y.; MAAS, J. L.; PAYNE, J. A.; GALLETTA, G. J. Ellagic acid content in small fruits mayhaws, and other plants. Jour. of Small Fruit and Viticulture, Baton Rouge, v. 2, n. 4, p. 11-49, 1994.

WELCH, R.; WANG, Y.; CROSSMAN JUNIOR, A.; PARK, J. B.; KIRK, K. L.; LEVINE, M. Accumulation of vitamin $\mathrm{C}$ (ascorbate) and its oxidized metabolite dehydroascorbic acid occurs by separate mechanisms. Jour. Biology Chem., U.S.A, v. 270, n. 21, p. 84-92, 1995.

ZHANG, D.; HAMAUZU, Y. Phenolics, ascorbic acid, carotenoids and antioxidant activity of broccoli and their changes during conventional and microwave cooking. Food Chem., London, v. 88, n. 4, p. 503-509, 2004. 
